DNA mismatch

repair MutS
DNA mismatch repair MutS core

$$
\text { DNA }
$$

MUS81 polymerase

beta
DNA repair nuclease;

XPF-type/helicase

SPB4 P-loop containing nucleoside triphosphate hydrolases

DNA/RNA helicase

\section{Clathrin coat} assembly

\section{Clathrin adaptor} mu subunit
Fig. S5. Cheung et al., 2008

1,000 Amino acids
DNA mismatch

repair 